\title{
Hypothermia Risk, Monitoring and Environment Control in Operating Rooms
}

\author{
G. Cannistraro ${ }^{1^{*}}$ and M. Cannistraro ${ }^{2}$ \\ *1 D.I - Department of Engineering, University of Messina, Messina, Italy \\ ${ }^{2}$ Freelance Engineering, University of Messina, Messina, Italy
}

Email: gcannistraro@unime.it

\begin{abstract}
The air-conditioning systems in operating rooms must be able to ensure at the patients at the surgical team a high level of comfort indoor. There is many factors to consider and analyze in order to prevent the occurrence of problems such as hypothermia of the patient, the thermal discomfort for the medical team, and not least, pollution by anesthetic gases. The thermal comfort conditions within the operating rooms can be obtained by controlling microclimatic parameters such as: temperature, relative humidity and air velocity. In an environment maintained in the condition of health and thermal comfort are minimized risks related to the onset of post-operative complications. In this paper we present some studies reported in the literature on the methods used for environmental monitoring and control of operating rooms and HVAC systems; they are treated in the methodologies actually used to obtain a hospital environment in conditions of healthiness and thermal comfort. Are reported the result some simulations, obtained with the use of a model of the operating room in real scale, in them are analyzed ventilation rates suitable to obtain the chemical dilution of anesthetic gases and contaminants physical-biological. In the simulations we have determined the microclimatic parameters (air humidity and temperature) for prevent risks for patients such as hypothermia, and to ensure the comfort of the surgical team.
\end{abstract}

Keywords: Environment control, Monitoring, Hypothermic risk, Operating rooms, Air climatization plants.

\section{INTRODUCTION}

Some of the major problems manifested by by patients undergoing general anesthesia into the operating rooms they are represented by: hypothermia; chills; increased body temperature; peripheral vasoconstriction; these problems generally occur in elderly and in the young persons.

Hypothermia in patients subject to surgery under general or local anesthesia is related to inhibition of their thermoregulatory system and the thermal exchanges suffered inside the operating room.

Several studies [1-16] have shown how a patient during a surgical intervention surgery of duration greater than one hour, reaches conditions of hypothermia under the combined effect of the following factors:

- Anesthesia;

- Exposure to cold drafts;

- Infusion of fluids (including blood) at room temperature;

- Increase in losses of heat towards the external environment because of the surgical incision which subjects the internal organs to direct exposure to air.

Hypothermia can cause several complications such as chills, long time of reactivation, impairment postoperative of coagulation, possibility of episodes of ischemic heart disease, and to lowering the immune system's defenses against infections of surgical wounds.

To avoid such problems, a study [7] suggests to maintain the temperature into the operating rooms a values greater than $26^{\circ} \mathrm{C}$, generally calls "rooms warm".

The values suggested by ISPESL, for the relative air humidity are: between $40 \%$ and $60 \%$ and for the air temperature of $20^{\circ} \mathrm{C}$ and $24^{\circ} \mathrm{C}$.

Besides the problems of hypothermia of patients during surgical procedures, there are several factors that can cause numerous infections in operating theaters and adjacent places, among these are:

- Type of surgical operation performed on the patient;

- Introduction of external material;

- Ventilation rate is not appropriate in the surgical area;

- Level of pressurization of the climatization plant;

- Immune status of patients;

- Prophylactic antibiotics and so on.

Many pathogenic infections are generated by the presence of bacterial flora present on the skin of the patient and medical personnel.

Possible remedies are:

- Sterilization of masks and gloves with liquid repellents which do not allow the penetration of bacteria; 
- An appropriate information of the medical staff on how to maintain sterile the operating tools;

- Minimization of the number of people within operating rooms, so as to avoid inappropriate flows of ventilation.

- Ventilation systems equipped with efficient filters

To obtain this, they must be used filters which guarantee an absorption between $80 \%$ and $95 \%$ of the polluting substances.

Even today there are no general rules that define the limits of contents of bacteria in the operating rooms, given the high values of ventilation.

In the European and non-European countries, are established some guidelines based on their experience in the workplace

\section{MONITORING AND CONTROL OPERATING ROOMS}

The operating rooms in hospitals, surely represent environments that require special attention from the point of view of environmental monitoring, as for the microclimate parameters and microbiological and chemical characteristics of the air; everything regardless of the type of surgical operation that is being carried.

The operating theaters are complex environments that require particular and constant attention and careful precautions to ensure the safety of the patient and medical personnel.

In the operating rooms the patients are exposed to dangers characterized by two main factors [16-22]:

- Chemical risk;

- Biohazard.

The chemical risk is mainly due to the presence of pollutants in the environment, caused particularly by the anesthetic gases.

The pathogenic substances in the atmosphere, increase the biological risk and cause the rise of infectious diseases in people at risk.

Some studies reported in the literature [16], referred that in the United States, in 1992 the costs related to the treatment of infections in surgical environments, reached a cost of 1, 600 million dollars; in Italy this cost has reached 1500 million euro per year.

The average cost of a surgical infection is estimated between EUR 3.500-8000.

And this is the reason why in recent years many studies have mainly involved environmental pollution within the operating rooms.

This is articulated through monitoring and control systematic of the microclimate, on the air microbial determination and measurements of the environmental concentrations of anesthetic gases.

The difficulty in the choice of microclimate parameters to maintain inside the operating room, is extremely high, this is because there is a need to reconcile many different factors that have the following origins:

- Homeothermy of patients;

- Thermal comfort of the medical team;

- Reduction of the microbiological components of air;

- Diluting the concentration of anesthetic gases in the air

To modern ventilation systems in operating rooms it is given the task of reducing the phenomena of chemical and microbiological pollution.
Unfortunately, the results are often not very satisfactory, and their operation is not suitable to ensure the minimum level of comfort for all patients, also because these often have different needs. In fact, during the surgical intervention a patient often undergoes violent cooling processes of the body, caused both by the low thermal resistance of her clothing, which by low temperatures and high air turbulence in the vicinity of the operating table.

These conditions of thermal discomfort are favored by the phenomena of peripheral vasoconstriction, caused by anesthetics that slow the blood flow velocity on the epithelial layer, and reduce the heat flux on the upper part of the skin.

During surgery, the team surgical is subject to conditions of global warming caused by metabolic activity in conditions of physical stress, the major heat flow radiated by the light sources, the thermal resistance of the clothing worn, and especially -caso interventions orthopedic- protections for the presence of x-ray.

In the literature, the adverse effects on patients are very well codified; these represented the cause of hypothermic presented in $30 \%$ of patients during surgery or in the next stage, caused by the combined effects of anesthesia and indoor climatic conditions.

However, these opposite conditions, including the degree of discomfort for patients and the medical team, now is not yet the subject of a systematic study of the phenomena involved, because this secondary event, is regarded as the inevitable relationship between the routine activities of an operating room; so it is a result and because of the absence of adequate scientific information.

\subsection{The control of the states hypothermic}

The hypothermic states can be controlled continuously by monitoring the $t_{\text {body }}$, body temperature calculated from the equation and Brock Zeisberger:

$$
T_{b o d y}=0,87+T_{\text {skin }}
$$

For the calculation of $\mathrm{T}_{\text {skin }}$ used in (1), the literature suggests many formulas: the most reliable seem to be those proposed by [11] with 7 measurement points in various parts of the body, compared to the 6 points proposed by [12] and 3 points, proposed by Olesen $[13,14]$

Trans and others [15-16] in a recent study on a group of individuals of different age and sex, have suggested a correlation between the tympanic temperature and average temperature $\mathrm{T}_{\text {skin }}$ and the blood level of the urinary bladder.

To overcome the unpleasant problem of the homeothermy of the patient, it is preferred not to act directly on the regulation of air flows of air conditioning system of the whole the operating room, it is preferred instead to act directly on the patient, increasing its body surface temperature, conveying on it hot air currents or localized using special mats heated, see Figure 1, and, gimmicks that because of the phenomena of vasoconstriction, may in certain cases be unnecessary.

\section{METHODS OF INVESTIGATION}

From the above it is inevitable and necessary to find appropriate methods of investigation that allow the study of the phenomena of interest from various points of view (physical, chemical, microbiological, clinical and metabolic). 


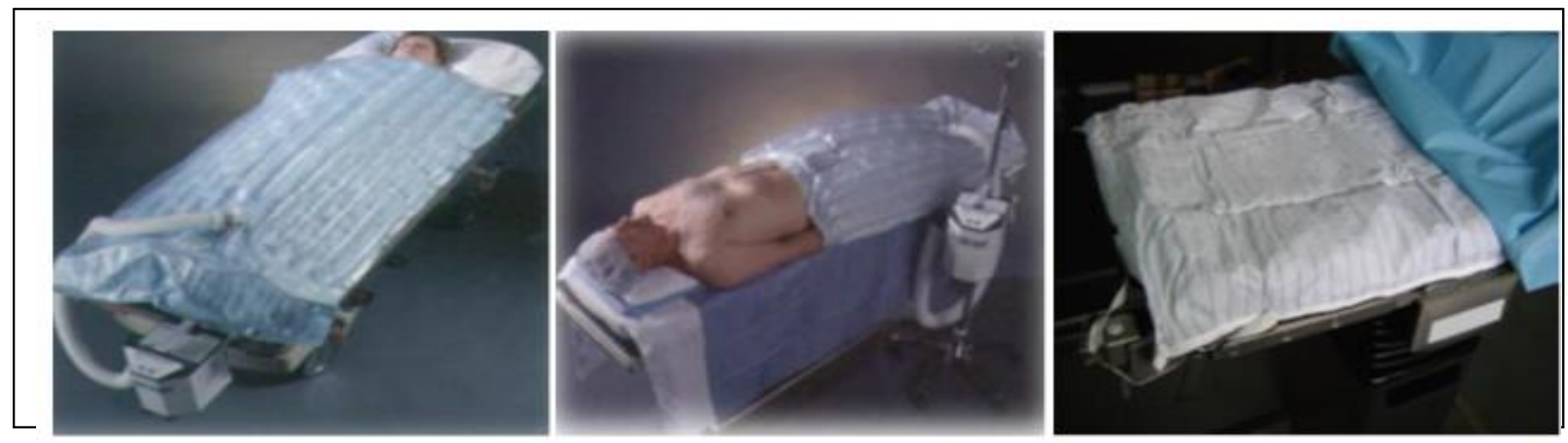

Figure 1. Blanket of heating used for local warming

A multidisciplinary investigation is described in order to deepen the understanding of the causes of the phenomenon covered.

Is been artificially reproduced a space to simulate situations of operating theaters, for investigate experimentally both on the events of pollution, which on the local discomfort, also through direct surveys obtained from the responses of operating rooms that actually exist, where is possible to analyze the sources of pollutants in reference at their use.

To this end, the research was divided into the following phases:

Clearly this suggests at researchers a type of research to get better understanding of the phenomena, and the pollution cause of the operating theaters with no-conditions of comfort for patients and the medical team.

An analysis based on the determination of some general parameters: the total bacterial and fungal amount, it can provide valuable information.

For the sampling of microbiological agents contained in the powders have been used some portable samplers that aspire air at a constant speed, this after passing through a metallic tube provided with small holes arrives on a underlying plate containing a suitable medium for the cultivation and isolation of microorganisms.

Subsequently the plates are analyzed in the laboratory to count the number most probable of microorganisms per cubic meter of sample analyzed.

- Analysis of the HVAC system (system type, features and performance of its components;

- Position of extraction areas of the exhaust gas, for analyzing contamination of the powders, coming from the outside and those due to air recirculation;

- Microbiological testing air and dust into the conduits;

- Qualitative analysis of the filtration system;

- Use of sensors, with any greater precision, to determine the concentration of anesthetic gases into air of the operating room;

- Critical analysis of the results to characterize the exact parameters of correlation between the amount of pollutants, the ventilation rate necessary to dilute these pollutants and the type of ventilation system.

The study of microbiological agents is certainly difficult, because, as is reported in the literature, there is a multitude of biological pathogens (parasitic fungi, bacteria, viruses...) who, individually or in conjunction with each other, can cause the increase in diseases.

The lack of appropriate knowledge of contagion, and sources of microbiological pollution and their importance, have determined the use in the air conditioning systems of the operating theaters with high numbers of air changes (by $\mathrm{R}=15$ to $150 \mathrm{vol} / \mathrm{h}$ for specific applications), with negative incidence of the occupants (patients and medical staff).

The ventilation system of an operating room must therefore be able to maintain an ambient healthy and comfortable for the medical staff and for the patient, this can be achieved reducing the risk of contamination through a suitable filtering of the air and through the use of a particular system of distribution flow within the chamber.

In the Italian hospitals are largely used air-conditioning systems with constant flow; however, these systems are not entirely suitable to dilute the pollutant load in the air of operating rooms.

A constant flow of the air exchange is imposed by DPR $n$. 37 of 14.01 .97 , by value $R=15 \mathrm{vol} / \mathrm{h}$, at value $R=20 \mathrm{vol} / \mathrm{h}$, for high induction systems, is sometimes overestimated, as it is sometimes underestimated. An increase of air volumes up to $\mathrm{R}=20 \mathrm{vol} / \mathrm{h}$ may cause undesired thermal discomfort of patient hypothermia and at the health care team.

Not neglecting then the economic problems resulting from higher energy consumption required by these parts.

A high value of the environmental pollution in an operating room is caused by significant concentrations of anesthetic gases, among them nitrous oxide is the most common.

In some studies environmental of operating rooms, the value of nitrous oxide has been used as an indicator of the pollution level, along with other halogenated gases present also in a significant amount.

Many scientific studies have shown that the effects of the intake of nitrous oxide and halogenated gases in animals and men may be carcinogenic, nephrotoxic, hepatotoxic, myelotoxic and able to cause abortions in pregnant subjects.

The workers in conditions of risk exposure to anesthetic gases is estimated in 50,000 is understandable then the importance of this issue.

In addition, the conditions that determine the quantity of anesthetic gas released inside an operating theatre are random and uncontrollable.

The value of the emission of nitrous oxide and halogenated gases depends by following factors: the efficiency and the maintenance of the tools used for anesthesia, the type of anesthesia (intubated or anesthetized with mask, directly in operating room, etc.) the habits and behavior of the medical team. It is difficult to characterize the emissions of an anesthetic gas, these therefore must to consider as a random variables. 


\subsection{The laboratory Certeca}

An experimental system was built in the Laboratory of the University of Ferrara CERTECA [17-20], has been installed a monitoring system (see Figure 2 and Figure 3), comprising:

- A rehearsal ambient

-An HVAC system (heating, ventilating, and air conditioning)

- A monitoring environmental system

- An environmental control unit

A test chamber (see Figure 3) was designed to recreate in a large scale a confined environment of variable size between $4.80-7.20 \mathrm{~m}$, and a height of $3.30 \mathrm{~m}$

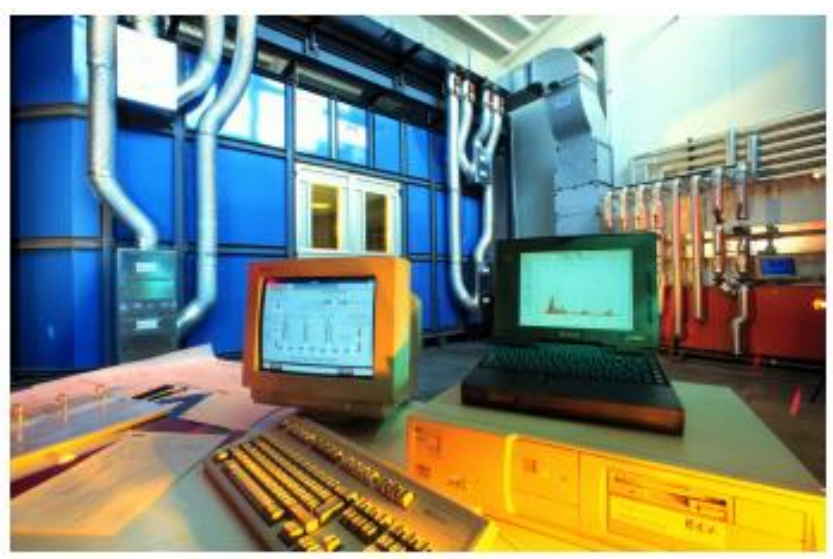

Figure 2. Monitoring and control unit

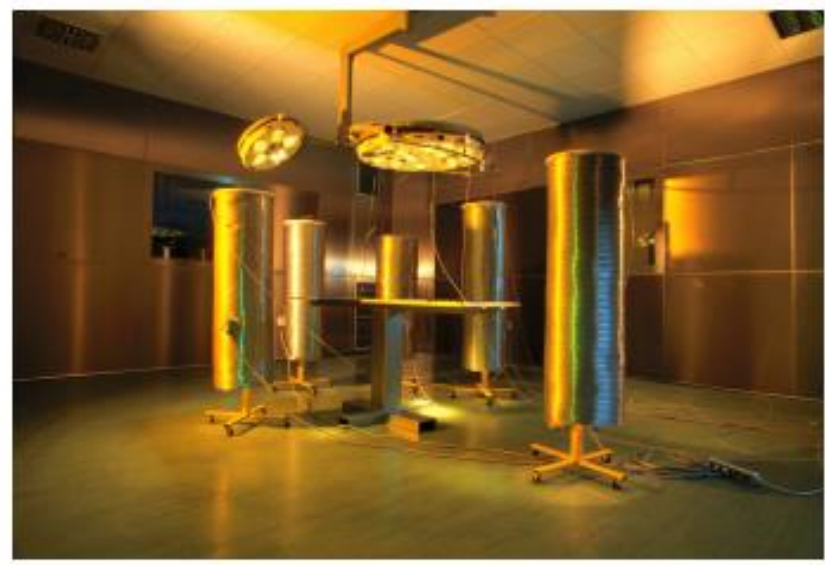

Figure 3. Test chamber with variable dimensions

A modular structure, geometrically and dimensionally variable, represents the environment; this consists of a series of panels that can be equipped with supply ducts and extraction air, connected to ventilation plant.

The operation room present some the panels transparent so as to observe from the outside and shoot the pictures and movies

The modular panels, easily removable, allow the opportunity to experiment with different solutions to air climatization by acting in air extraction and by on the number of air change.

In addition the vents are motorized for control of the air flows in entrance and into extraction.

This configuration allows you to simulate the possible configurations of pollution: dust, bacteria, gas pollutants etc.

The ceiling of the operating room has the same characteristics of modularity of the walls.

The climate parameters: temperature, relative humidity and atmospheric pressure of the air inside the air conditioning system they can be controlled as a function of the external parameters.

To simulate the processes of environmental pollution, the air capacity of the air conditioning system may be mixed with a quantity of particle density and the predetermined concentration.

Consequently, you can vary the flow of ventilation air in function of the pollutants by dilute in the room.

In previous studies it has been shown that air conditioning systems with variable flow, are more effective for the characteristics of dilution of pollutants than systems at flow constant.

In previous studies it has been shown that air conditioning systems with variable flow, are more effective for the characteristics of dilution of pollutants than systems at flow constant.

With this type of system it is possible investigate on the type of pollution present in the operating room, with the exclusion of other possible sources of microbiological.

The characterization of the source is particularly complex and requires a time comprised between 48 and 72 hours, then it is preferred the assessment of pollution of the operating room through the concentration of the particles (ISO 14644).

In the literature there is no correlation between the particle and the microbiological concentrations, as is being investigated with this procedure.

From this reason it is necessary to do specific studies in the laboratory and in operating rooms

Another possible system, independent from the first, allows in any part of the environment investigated the issue of another tracer gas.

With the two systems described is possible highlight the movement air inside the operating room, and identify zone of stagnant air, and then study the spread of the pollutants for the different air flows outside.

In particular, one can constantly monitor all thermodynamic properties, functional and chemicalphysical properties of the air (internal temperature test environment, outside air temperature, air pressure inside and outside the test cell, relative humidity of 'indoor and outdoor air, the field of air velocity inside the room, the concentration of pollutant gases, and concentration of the particles, the air flow in extraction for each grid).

The direction of air flow for each grid are controlled manually.

The system monitoring and acquisition of data is constituted by a series of sensors connected to an apparatus acquisition interfaced with PC. 


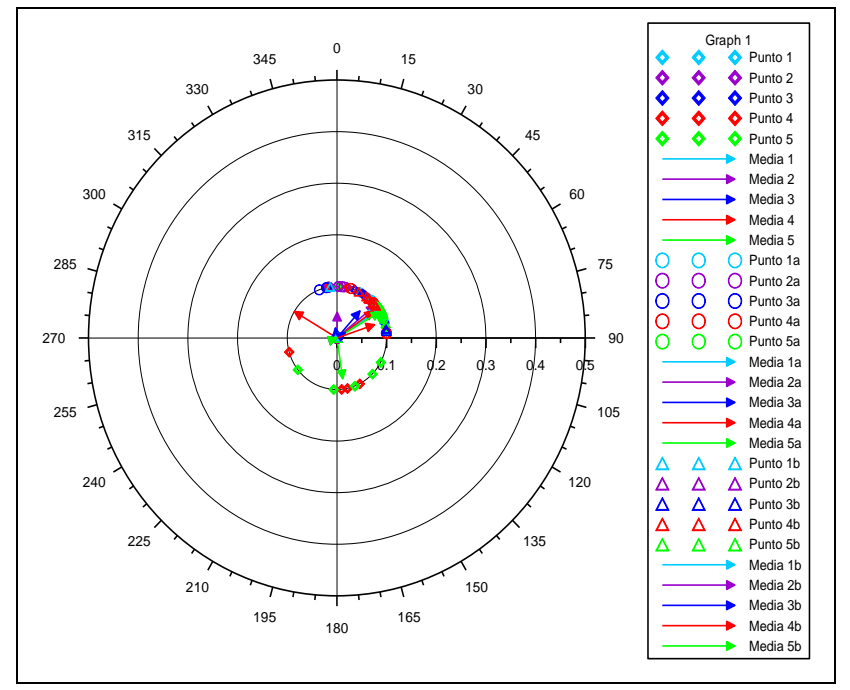

Figure 4a. Air speed, in the exit of the vent of ventilation A

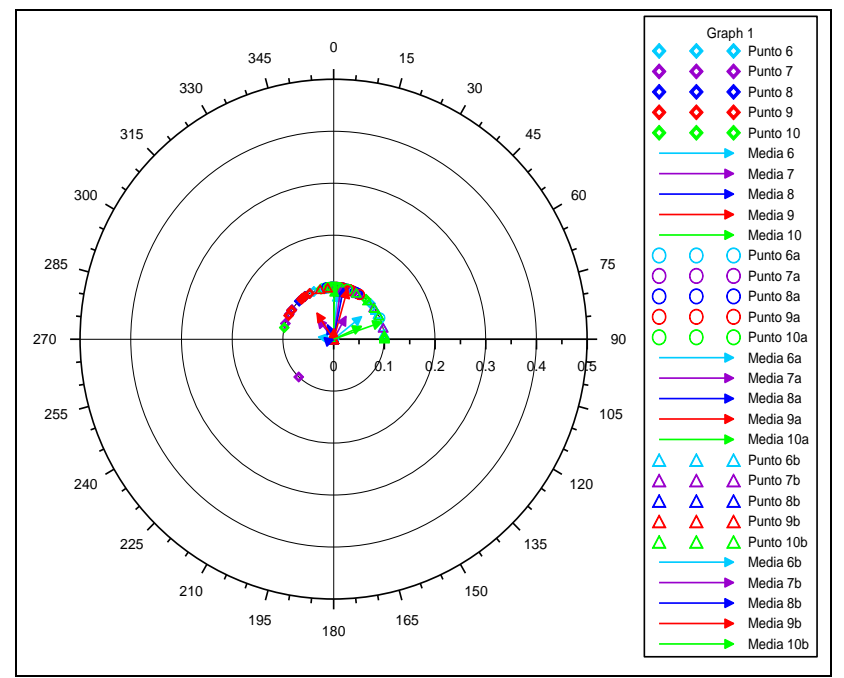

Figure 4b. Air speed, in the exit of the vent of ventilation B

With it you can compare the results obtained with the various procedures of numerical simulation.

A supervisor computer allows editing of any single parameter of the system through a user interface.

With all the acquired data the control system is able to automatically vary the configuration of the ventilation system of the operating room in function to specific algorithms developed.

With this system it is possible to determine, within the test chamber, the microclimate you want, and also the levels of concentration of particles and toxic substances.

So how similarly they determine the conditions of comfort in the various type of the buildings and assessment of pollutants in the environmental monitoring $[21,26]$.

Experimental tests of the system were carried out in the field for some operating rooms by Italian Hospitals, where you have installed a supervision system. In the Figure $4 / \mathrm{a} / \mathrm{b} / \mathrm{c} / \mathrm{d}$ they are shown the polar curves of the air speed in four vents of ventilation, inside in the environment monitored, in the positions $\mathrm{A}, \mathrm{B}, \mathrm{C}, \mathrm{D}$ at height $\mathrm{h}=1.50 \mathrm{~m}$, with air flow of $18 \mathrm{Vol} / \mathrm{h}$.

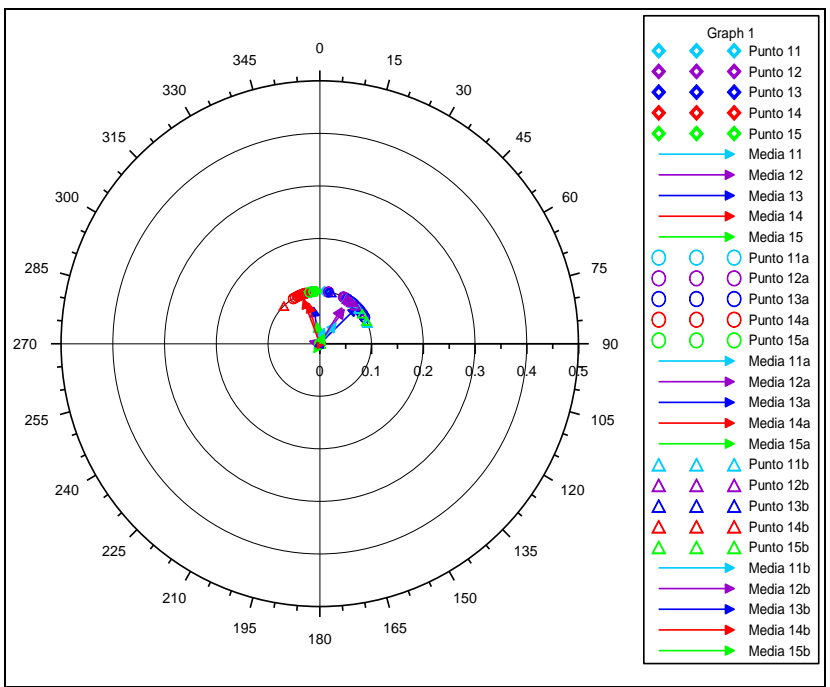

Figure 4c. Air speed, in the exit of the vent of ventilation C

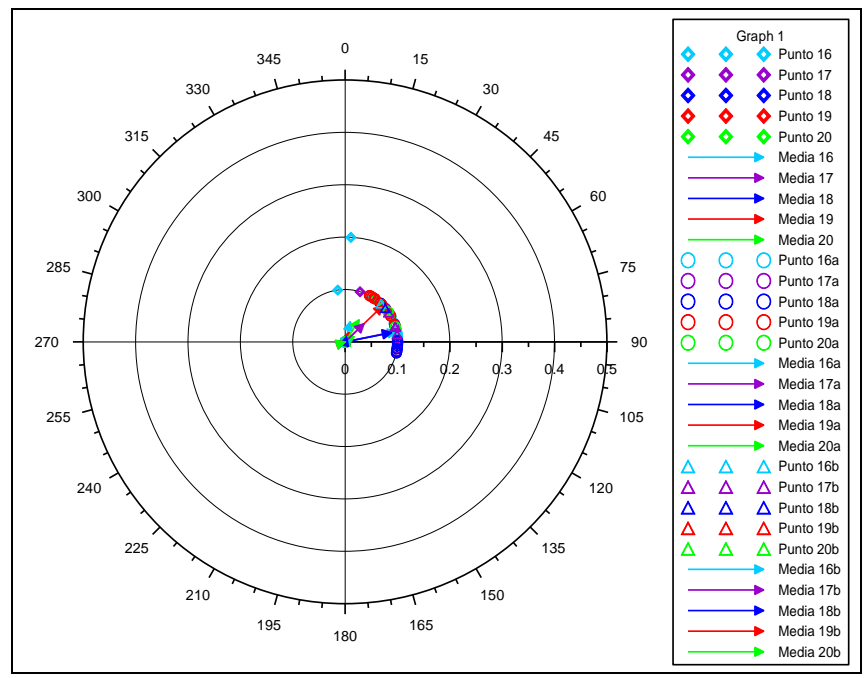

Figure 4d. Air speed, in the exit of the vent of ventilation D

In the Figure $5 \mathrm{a} / \mathrm{b} / \mathrm{c} / \mathrm{d}$, are shown the graphs threedimensional patterns the air speed of the four vents of ventilation inside in the environment monitored, in the positions A, B, C, D placed at the height $\mathrm{h}=2,75 \mathrm{~m}$, with air flow of $18 \mathrm{Vol} / \mathrm{h}$.

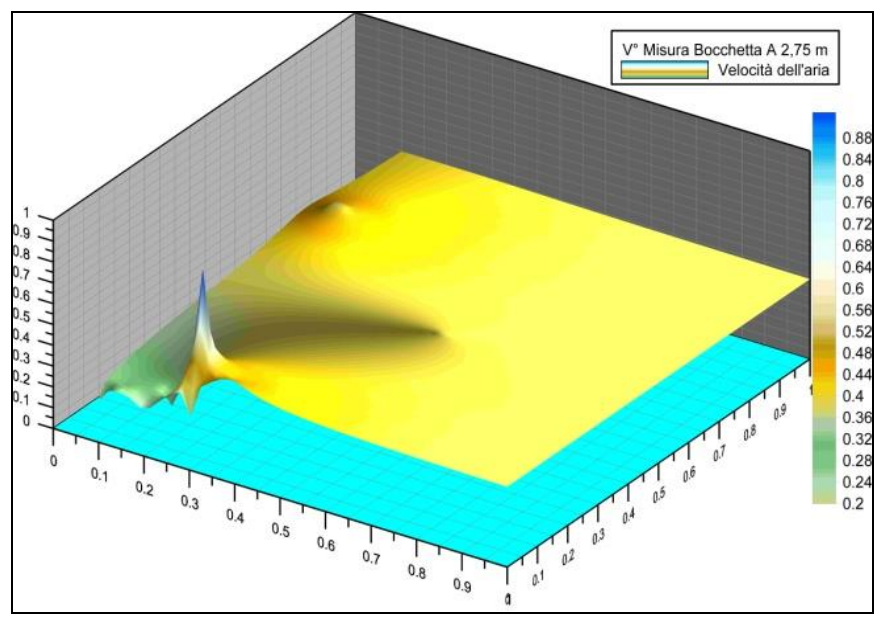

Figure 5a. Air speed, in the exit of the vent of ventilation A 


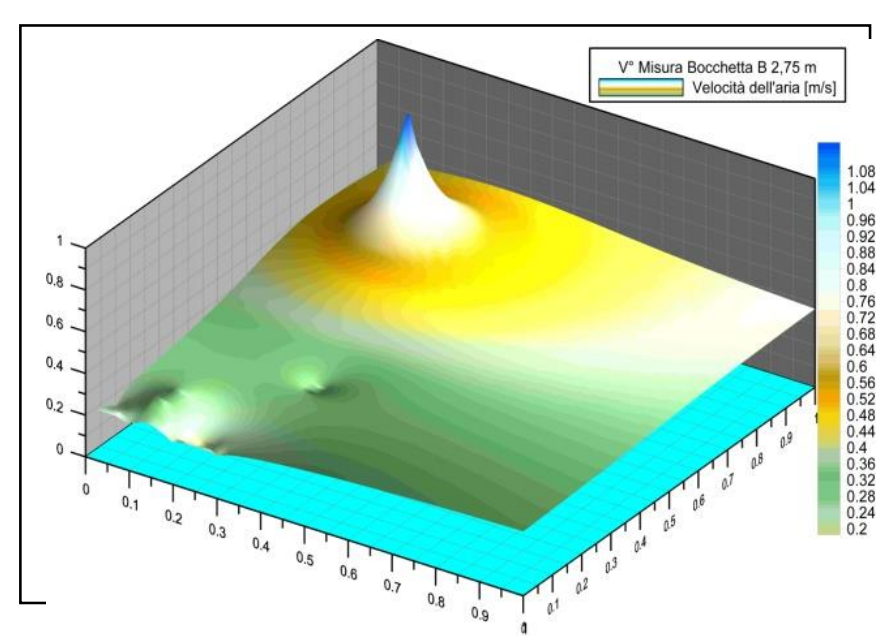

Figure 5b. Air speed, in the exit of the vent of ventilation B

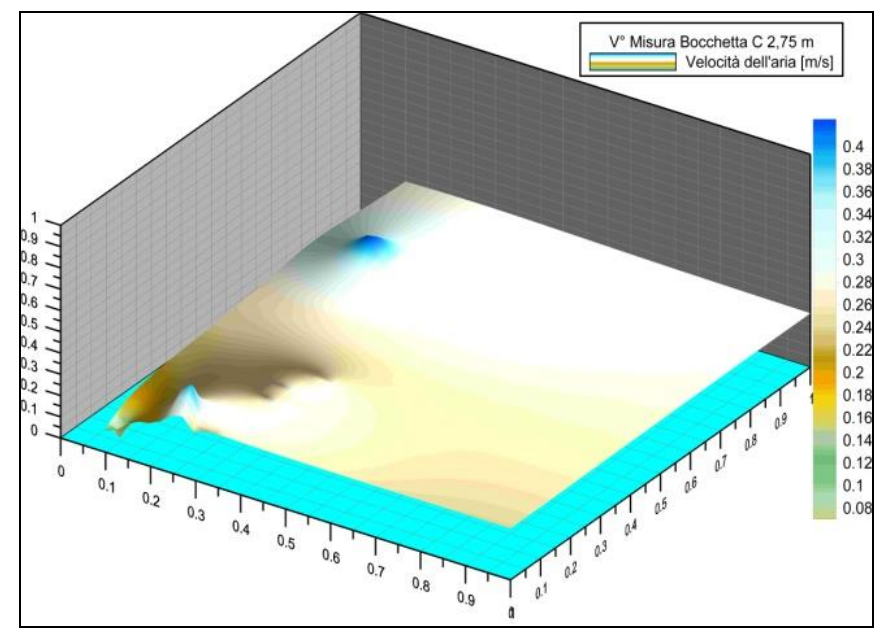

Figure 5c. Air speed, in the exit of the vent of ventilation $C$

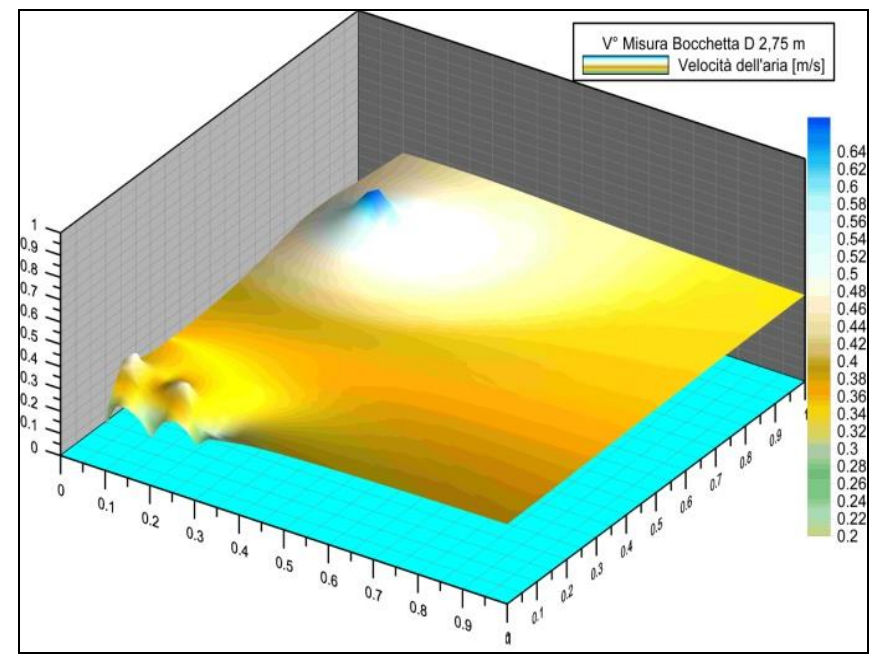

Figure 5d. Air speed, in the exit of the vent of ventilation D

\section{CONCLUSIONS}

With the use of a model of the operating room in real scale, can be determined ventilation rates adequate to obtain the dilution of chemicals, anesthetic gases and contaminants physical-biological. It is also possible to determine the climatic parameters (temperature and relative air humidity) necessary to avoid the risk of hypothermia of the patient and to ensure the thermal comfort to the surgical team.

Through a system of variable panels removable we can experience more solutions to condition the air in the same room, rearranging the placement of air inlets and extraction grilles or by changing their number.

A dedicated server allows you to acquire the data and create a database that allows you to describe in detail the parameters.

The air conditioning system with flow inlets modulable air, able control for each of them: the flow rate, temperature, relative humidity, air velocity, is can ensure optimum climatic conditions for the patient and for the team doctor.

Therefore, this type of system is able to determine, inside the test chamber, the conditions of the desired microclimatic parameters, in terms thermo hygrometric, and also determine the level of concentration of the particles or toxic substances.

The simulations in the test chamber are can determine the microclimatic parameters (air humidity and temperature) for prevent risks for patients such as hypothermia, and to ensure the comfort of the surgical team.

\section{REFERENCES}

[1] A. Azara, M. D. Masia, I. Maida, G. Sotgiu, G. L. Giaconi and R. Gusinu, "Inquinamento ambientale nelle sale operatorie - Nota II: condizioni microclimatiche e microbiologiche," View \& Review, pp. 4-10, 2000.

[2] Nadia Oberhofer, "Comparison of Two Novel FFDM Systems with Different a-Se Detector Technology: Physical Characterization and Phantom Contrast Detail Evaluation in Clinical Conditions," Lecture Notes Computer Science, 2010.

[3] J. Huang and A. Kurz, "Body warmer and upper extremities position affect the accuracy of cutaneous thermometers during anesthesia," Journal of Clinical Anesthesia, vol. 13, no. 4, pp. 241-243, 2001.

[4] S. M. Frank, K. M. Tran, L. A. Fleisher and H. K. Elrahmany, "linical importance of body temperature in the surgical patient," Journal of Thermal Biology, vol. 25, no. 1-2, pp. 151-155, 2000.

[5] A. Kurz, "Prevention and treatment of perioperative hypothermia," Current Anaesthesia \& Critical Care, vol. 12, no. 2, pp. 96-102, 2001.

[6] T. Kasai, M. Hirose, T. Matsukawa, A. Takamata and Y. Tanaka, "The vasoconstriction threshold is increased in obesepatients during general anaesthesia," Acta Anaesthesiologica Scandinavica, vol. 47, no. 5, pp. 588-592, 2003.

[7] J. de Witte and D. I. Sessler, "Perioperative shivering, physiologyand pharmacology," Anesthesiology, vol. 96, no. 2, pp. 467-484, 2002.

[8] P. Sramek, M. Simeckova, L. Jansky and V. Zeman, "Human physiological responses due to immersion into water of different temperatures," European Journal of Applied Physiology, vol. 81, pp. 436-442, 2000.

[9] M. Bock, B. Sinner, M. Gottlicher, E. Simon, E. Martin and J. Motsch, "Involvement of serotonergic pathways in postanaesthetic cold defence: dolasetron prevents shivering," Journal of Thermal Biology, vol. 27, no. 2, pp. 159-166, 2002. 
[10] K. Bruck and E. Zeisberger, "Adaptive changes in thermoregulation and their neuropharmacological basis," Pharmacology and Therapeutics, vol. 35, no. 1-2, pp. 163-215, 1987.

[11] C. Huizenga, H. Zhang, E. Arens and D. Wang, "Skin and core temperature response to partial- and wholebody heating and cooling," Journal of Thermal Biology, vol. 29, no. 7-8, pp. 549-558, 2004.

[12] E. Martini, R. Bruschi, L. Fontana, S. Savini and M. M. D'Errico, 'La valutazione ambientale delle Sale operatorie: esperienza in una azienda ospedaliera marchigiana," View \& Review, pp. 21-28, 1999.

[13] T. M. Smith and A. M. Emmerson, "Surgical site infection surveillance," J. of. Hospital Infections, 45, pp. 173-184, 2000.

[14] B. W. Olesen, "Howmany sites are necessary to estimate a mean skin temperature?" in Thermal Physiology, J. R. S. Hales, New York: Raven Press, 1984, pp. 34-38.

[15] K. M. Tran, S. M. Frank, H. K. El-Rahmany, N. S. Ghoneim, L. J. Kim and R. A. Barnes, "Thermal and hemodynamic responses to postoperative rewarming with a sub-atmospheric pressure device," Journal of Thermal Biology, vol. 25, no. 1-2, pp. 191-196, 2000.

[16] Y. G. Lv and J. Liu, "Effect of transient temperature on thermo receptor response and thermal sensation," Building and Environment, vol. 42, no. 2, pp. 656664, 2007.

[17] L. Alberani, G. Cannistraro, G. Lupo, S. Mazzacane, D. Milone and A Piccolo "Climatization in operating theatres," Climamed Congreso mediterràneo de climatizaciòn, Madrid, pp. 1-9, 2005.

[18] S. Mazzacane, L. Alberani, C. Giaconia, S. Costanzo, A. Cusumano, and F. Margelli, "Sale operatorie: Studio dei fenomeni di inquinamento fisico, chimico e microbiologico," La Termotecnica, vol. 61, pp. 79-85, 2007.

[19] S. Mazzacane, C. Giaconia, S. Costanzo, and A. Cusumano, "A survey on the thermal conditions experienced by a surgical team," Indoor and Built Environment, vol. 16, no. 2, pp. 99-109, 2007.

[20] S. Mazzacane, C. Giaconia, S. Costanzo, and A. Cusumano, "A Proposed Methodology to Control Body Temperature in Patients at Risk of Hypothermia by means of Active Rewarming Systems," Hindawi Publishing Corporation BioMed Research
International, ID136407, pp. $10 . \quad$ DOI: 10.1155/2014/136407.

[21] G. Cannistraro, M. Cannistraro and R. Restivo. (2015). Some observations on the radiative exchanges influence on thermal comfort in rectangular openspace environments. Int J Heat \& Tech. [Online]. 33(2), pp. 79-84. Available: http://www.iieta.org/sites/default/files/Journals/HTEC H/33.2 13.pdf. DOI: 10.18280/ijht.330213.

[22] G. Cannistraro, M. Cannistraro and R. Restivo. (2015). The local media radiant temperature for the calculation of comfort in areas characterized by radiant surfaces. Int J Heat \& Tech. [Online]. 33(1), pp. 115-122. Available:

http://www.iieta.org/sites/default/files/Journals/HTEC H/33.1_16.pdf. DOI: 10.18280/ijht.330116.

[23] G. Cannistraro, M. Cannistraro and R. Restivo, "Smart control of air climatization system in function on the values of mean local radiant temperature," Smart Science, vol.3, no.3, pp.157-163, 2015. DOI: 10.6493/SmartSci.2015.331.

[24] G. Cannistraro, M. Cannistraro and R. Restivo. (2013). Messina's historical buildings after the earthquake of 1908: energy and environmental analysis through a global screening methodology. Int. J Heat \& Tech. [Online]. 31(2), pp. 155, 158. Available: http://www.iieta.org/sites/default/files/Journals/HTEC H/31. 2 21.pdf. DOI: 10.18280/ijht.310221.

[25] A. Cannistraro, G. Cannistraro, M. Cannistraro and A. Galvagno and G. Trovato. (2015). Evaluation on the convenience of a citizen service district heating for the residential use. A new scenario introduced by high efficiency energy system. Int J Heat \& Tech. [Online]. 33(4), pp. 167-172. Available: http://www.iieta.org/sites/default/files/Journals/HTEC H/33.4_21.pdf. DOI: 10.18280/ijht.330421.

[26] G. Cannistraro, M. Cannistraro, A. Galvagno and G. Trovato, "The cogeneration in service hotel complexes. A case study," International Congress WSEAS, Venice, pp. 29-31, Jan. 2016.

\section{NOMENCLATURE}

$\mathrm{T}_{\text {body }}$ body temperature, $\left[{ }^{\circ}\right.$ degree $]$

$\mathrm{T}_{\text {skin }}$ temperature of the skin, $\left[{ }^{\circ}\right.$ degree]

$\mathrm{R}$ rates of ventilations, [volumes $/ \mathrm{h}$ ] 